\title{
Experiências extensionistas do grupo de melhoramento de milho-pipoca da UENF: Interagindo com a comunidade de Campos dos Goytacazes
}

\author{
Extensionist experiences of the UENF popcorn breeding group: Interacting with the community of \\ Campos dos Goytacazes \\ Experiencias extensionistas del grupo de mejora de palomitas de maíz de la UENF: Interactuando \\ con la comunidad de Campos dos Goytacazes
}

\section{Resumo}

Relatam-se as principais percepções e experiências de ações extensionistas desenvolvidas pelo Grupo de Melhoramento de Milho-Pipoca (GMMP) da UENF. Tem-se como principal objetivo a promoção e o desenvolvimento da agricultura regional no Norte Fluminense por meio do cultivo de milho-pipoca. Em 2017, o GMMP visou à integração das pesquisas realizadas no âmbito do melhoramento da cultura, com os agricultores, por meio de dia-de-campo. No ano de 2018 e 2019 o objetivo do grupo foi conhecer o perfil socioeconômico dos comerciantes e dos produtores rurais do Norte Fluminense, com foco no milho-pipoca, por meio da aplicação questionários. Majoritariamente os comerciantes de pipoca possuem interesse em adquirir grãos de agricultores locais, bem como estes têm desejo de iniciar o plantio da cultura em parceria com a UENF, diversificando as culturas produzidas em suas propriedades, para as quais, sobretudo, prevalece a da cana-de-açúcar. A principal percepção foi que ao diagnosticar o possível mercado para venda dos grãos 
por parte dos agricultores, essa se torne uma cultura atraente para o cultivo regional. Em 2020 e anos subsequentes, as ações extensionistas do GMMP culminarão na transferência de tecnologia, dentre outras ações de incentivo, por meio da distribuição de sementes desenvolvidas pela Universidade.

Palavras-chave: Norte fluminense; Comerciantes; Agricultores; Distribuição de sementes.

\begin{abstract}
The main perceptions and experiences of extension actions developed by the Popcorn breeding Group (GMMP) of UENF are reported. The main objective is the promotion and development of regional agriculture in the North of Rio de Janeiro through the cultivation of popcorn. In 2017, the GMMP aimed to integrate the research carried out in the field of crop breeding, with farmers, through a field day. In 2018 and 2019, the group's objective was to learn about the socioeconomic profile of merchants and rural producers in the North of Rio de Janeiro, with a focus on popcorn, through the application of questionnaires. Most popcorn traders are interested in acquiring grains from local farmers, and they are willing to start planting the crop in partnership with UENF, diversifying the crops produced on their properties, for which, above all, sugarcane prevails. of sugar. The main perception was that when diagnosing the possible market for the sale of grains by farmers, this becomes an attractive crop for regional cultivation. In 2020 and subsequent years, the GMMP extension actions will culminate in the transfer of technology, among other incentive actions, through the distribution of seeds developed by the University.
\end{abstract}

Keywords: North of the state of Rio de Janeiro; Merchants; Farmers; Seed distribution.

\title{
Resumen
}

Se reportan las principales percepciones y experiencias de las acciones de extensión universitaria desarrolladas por el Grupo de Mejora de Palomitas de Maíz (GMMP) de la UENF. Nuestro principal objetivo es la promoción y desarrollo de la agricultura regional en el norte del estado de Río de Janeiro, a través del cultivo de palomitas de maíz. En 2017, el GMMP tuvo como objetivo integrar la investigación realizada en el campo de la mejora del cultivo, con los agricultores, a través de una jornada de campo. La interacción pretendida podría haber sido mayor, ya que el cultivo de palomitas de maíz en la región es incipiente y, en algún momento, desconocido. Se notó que la estrategia adoptada debe ser diferente para lograr una mayor interacción con los agricultores. En este sentido, en 2018 y 2019 nos dedicamos a conocer el perfil socioeconómico de comerciantes y productores rurales del norte del estado de Río de Janeiro, con un enfoque en las palomitas de maíz, mediante la aplicación de un cuestionario. La mayoría de los comerciantes de palomitas de maíz están interesados en comprar granos de los agricultores locales, así como estos están dispuestos a comenzar a sembrar el cultivo en alianza con UENF, diversificando los cultivos que se producen en sus propiedades, para lo cual, sobre todo, prevalece la caña de azúcar. La percepción principal fue que al diagnosticar el posible mercado de venta de granos por parte de los agricultores, este se convierte en un cultivo atractivo para el cultivo regional. En 2020 y años posteriores, las acciones de extensión del GMMP culminarán en la transferencia de tecnología, entre otras acciones de incentivo, a través de la distribución de semillas desarrolladas por la Universidad.

Palabras clave: Norte del estado de Río de Janeiro; Comerciantes; Agricultores; Distribución de semillas.

\section{Introdução}

O Laboratório de Melhoramento Genético Vegetal (LMGV) foi criado em 1993, como parte da Universidade Estadual do Norte Fluminense Darcy Ribeiro (UENF). A equipe de pesquisadores do LMGV atua em projetos que visam ao desenvolvimento de pesquisas que possibilitem o lançamento de cultivares melhoradas para o Norte e Noroeste Fluminense, e, também, para o país. Dentre os integrantes do LMGV, encontra-se o Grupo de Melhoramento de Milho-pipoca (GMMP), o qual atua essencialmente no desenvolvimento de novas cultivares adaptadas e recomendadas, sobretudo, para a região Norte Fluminense.

No Brasil, o milho-pipoca é um alimento muito apreciado e consumido e, principalmente, está associado a momentos de lazer e a salas de cinema (Amaral Junior et al., 2013; Lima et al., 2016). Ainda existe um vasto mercado a ser desenvolvido para a cultura do milho-pipoca no Brasil, dado o aumento da área plantada alcançar 223,0 \% nos cinco últimos anos (Kist et al., 2019). São poucas as Instituições e Universidades que desenvolvem pesquisas com o melhoramento da cultura. Cita-se a Embrapa Milho e Sorgo, o Instituto Agronômico de Campinas, a Escola Superior de Agricultura "Luiz de Queiroz", a Universidade Federal de Viçosa e de Lavras, a Universidade Estadual de Maringá e a UENF. A escassez de pesquisas com a cultura é um paradoxo, pois o milho-pipoca apresenta maior rentabilidade que o milho comum. De acordo com a bolsa de mercadorias brasileiras, a saca de $60,0 \mathrm{Kg}$ do milho-pipoca possuiu o preço médio de $\mathrm{R} \$ 60,00$, enquanto do segundo variou entre R\$46,00 e R \$ 29,50 (BBM, 2020). 
Um programa de melhoramento genético de milho-pipoca deve ter o objetivo de aumentar o rendimento dos grãos e da capacidade de expansão, visto que estas são as características de maior importância econômica para a cultura (Scapim et al., 2002; Xavier et al., 2019; Alexander e Creech, 1977). Os agricultores vendem os grãos para obter lucro, por isso, o que mais importa é a produtividade das cultivares. Por outro lado, os consumidores buscam melhores qualidades organolépticas, sobretudo associadas à capacidade de expansão (razão obtida entre a massa de grãos e o volume obtido após expansão, sob calor). Uma dificuldade encontrada pelos melhoristas da cultura, a qual foi demonstrada por diversos pesquisadores, foi a correlação negativa entre o rendimento e a capacidade de expansão dos grãos. Isso significa que aumentar o rendimento de grãos proporciona decréscimo na capacidade de expansão, e vice-versa (Carpentieri-Pípolo, 2002; Daros et al., 2004; Cabral et al., 2016).

Há meios de contornar essa associação negativa entre rendimento e capacidade de expansão, por meio da aplicação de estratégias de melhoramento genético apropriadas, culminando no desenvolvimento de uma cultivar promissora. Nesse sentido, o GMMP lançou uma variedade de polinização aberta (VPA), a UENF14, e dezenas de cultivares híbridas, as quais se encontram registradas no Ministério da Agricultura, Pecuária e Abastecimento (MAPA). Os trabalhos para obtenção da VPA UENF14, iniciados em 1998, foram realizados em germoplasma de milho-pipoca indígena, obtido por doação Institucional da ESALQ à Universidade de Brasília, para, finalmente, chegar até a UENF. Chegada na UENF, a antiga variedade indígena foi cruzada com uma variedade Norte Americana que apresentava resistência ao helmintosporiose (Exserohilum turcicum). Após a realização dos cruzamentos e condução dos experimentos para a seleção das melhores plantas, obteve-se uma variedade com elevada resistência à doença citada e com produtividade superior, denominada de UNB-2U, em homenagem à Instituição de origem, esta nova variedade foi melhorada por meio de seleção recorrente ao longo de 14 anos, onde foram realizados cinco ciclos de seleção, para aumentar a produtividade e a capacidade de expansão (Amaral Junior et al., 2013). Importante mencionar que o uso de VPAs é uma opção acertada para a agricultura familiar, dada a possibilidade de manutenção das sementes de uma safra a outra, com replantio das mesmas.

O sucesso de programas de melhoramento ocorre quando as cultivares lançadas são amplamente utilizadas pelos agricultores. As atuais cultivares lançadas pelo GMMP, estão sendo cultivadas em outros estados, como o Espírito Santo e Mato Grosso, e não estão sendo utilizadas na região em que foram desenvolvidas. As regiões Norte e Noroeste Fluminense, que têm na agropecuária sua principal atividade econômica, caracterizam-se tradicionalmente pela economia açucareira (Azevedo, 2004). Como uma alternativa à monocultura da cana-de-açúcar, estabelecida durante décadas nas regiões citadas, o milho-pipoca é uma opção viável. Em virtude de apresentar elevado valor econômico por área, além de ser comercializado por volume, trata-se de uma cultura rentável, não apenas para o produtor de grãos, mas também para o comerciante que produz a pipoca expandida (Xavier et al., 2019). Além disso, as monoculturas podem ocasionar problemas ao meio em que estão estabelecidas, como exaustão do solo e de nutrientes, predominância de pragas e doenças específicas e aumento do uso de defensivos agrícolas (Galerani, 2005). Diante disso, o milho-pipoca pode ser uma alternativa para implementar a diversificação de culturas.

Como potenciais produtores para os grãos de milho-pipoca na região campista, visto o intuito de agregação de renda e possibilidade de inserção de culturas alternativas, citam-se as famílias de agricultores assentados do município. A título de informação, na região Norte Fluminense existem cerca de 1.200 famílias assentadas que praticam a agricultura familiar, distribuídas em nove assentamentos, ocupando área próxima a 18.000 hectares (Campos Dos Goytacazes, 2018). Dentre estes, o Assentamento Zumbi dos Palmares, alvo de atuação das ações extensionistas do LMGV, abrange área de 8.500 hectares (Pedlowski, 2006), abrigando 507 famílias (INCRA, 2011). Particularidade do Assentamento citado é que sua formação ocorreu após a falência da usina de São João, devido à altas dívidas bancárias. A terras da antiga empresa foram desapropriadas pelo Instituto Nacional de Colonização e Reforma Agrária (INCRA), as quais foram distribuídas pelo Movimento Sem Terra às famílias assentadas pelas fazendas, em 1997 (Lewin, 2005). Apesar desse fato histórico, o local segue caracterizado pela produção de cana-de-açúcar (Xavier et al., 2019). 
O consumo de pipoca no município de Campos dos Goytacazes é bastante popular, o que pode alavancar a produção e aumentar a aceitação do cultivo de milho-pipoca, ancorada pelo elevado consumo que a cidade apresenta. Isto pode ser observado pelo expressivo número de carrocinhas de pipoca na região, em que são percebidas numerosas filas para a compra da pipoca expandida (Xavier et al., 2019). Uma vez lançadas as cultivares pelo GMMP, percebeu-se que há a necessidade de levar o saber, a tecnologia e os materiais desenvolvidos para as mãos dos agricultores, quer seja por meio de compra de híbridos via empresa de sementes, ou, o mais importante, por meio de doação de sementes da VPA, dada a particularidade da agricultura familiar que predomina na região.

Neste sentido, o objetivo foi descrever as atividades e as principais percepções das ações extensionistas do GMMP em projetos aprovados e desenvolvidos pela Pró-Reitoria de Extensão (PROEX) da UENF, que possuem como principal propósito desenvolver a agricultura local por meio do cultivo de milho-pipoca.

\section{Descrição das Atividades}

\subsection{As experiências do GMMP}

O GMMP vem atuando com Extensão Universitária desde 2017. Todos os projetos receberam apoio financeiro da PROEX, por meio de bolsas de estudos para os discentes da UENF e pelo Programa Universidade Aberta do Brasil (UAB). A equipe interna, normalmente, é composta por estudantes de Agronomia e de Ciências Biológicas, estes últimos procedentes do Centro de Educação Superior a Distância do Estado do Rio de Janeiro (CEDERJ). Via UAB, participaram estudantes de outras Instituições de Ensino, como por exemplo, o Instituto Federal Fluminense (IFF). Elemento fundamental para execução dos projetos, refere-se à presença de um interlocutor local. Nesse sentido, é possível destacar a participação de um assentado do Zumbi dos Palmares, João Sávio Monção Figueiredo, que foi o elo essencial para a "abertura de portas" no Assentamento, localidade alvo de ações. Sua presença possibilitou o intermédio da Equipe de Extensão com os produtores locais, além de guiarnos para a realização de entrevistas. Por muitas vezes, nossa Equipe tem sido composta também por estudantes de Pós-graduação do Programa de Genética e Melhoramento de Plantas da UENF.

A atuação integrada de todos os membros da Equipe, quer sejam estudantes de graduação, pós-graduação e docentes, foi tratada como uma prioridade, com o intuito de estreitar a relação do GMMP com os agricultores e os comerciantes. A cada ano as percepções adquiridas foram amadurecidas e, assim, fundamentaram a elaboração de estratégias de novas ações para o ano seguinte, gerando um novo plano de ação, porém, dando continuidade as ideias anteriores. Desde o ano de 2017, o GMMP, concluiu três Projetos de Extensão consecutivos. No ano de 2020, está em desenvolvimento o quarto Projeto. Todos eles visam à popularização da cultura do milho-pipoca, tornando possível levar as resultantes das pesquisas realizadas no interior da Universidade para os produtores e comerciantes locais do município de Campos dos Goytacazes.

\subsection{Lançamento de cultivares híbridas de milho-pipoca fundamentado em programa de melhoramento e ações} extensionistas para as regiões Norte e Noroeste Fluminense (ano 2017)

O lançamento de nova cultivar constitui-se em laboriosa e importante conquista de pesquisa, via melhoramento genético vegetal. Esse feito pode melhorar as condições socioeconômicas dos produtores rurais, bem como, serve de incentivo ao agronegócio e alavanca a agricultura familiar. O GMMP, na tentativa de despertar o interesse e divulgar as novas cultivares híbridas de milho-pipoca, que, na ocasião estavam em fase de registro no MAPA, para os produtores rurais do Norte e Noroeste Fluminense e consumidores, projetou atividades para atender esse fim, as quais serão descritas a seguir.

As cultivares lançadas pelo GMMP, junto ao MAPA, foram: UENF UVV 01, UENF HS 01, UENF HS 02, UENF HS 03, UENF HS 04, UENF HS 05. Ressalta-se a natureza genética das cultivares lançadas. Todas eram híbridas, o que significa dizer que são detentoras do chamado "vigor híbrido". Isto é, as plantas são altamente produtivas e possuem homogeneidade 
quanto às suas características desejáveis (altura de plantas, número de espigas, resistência a doenças, dentre outras). No entanto, existem algumas desvantagens no uso dessas cultivares, como por exemplo, a impossibilidade de aproveitamento das sementes para cultivo de uma safra para a outra, além dos maiores custos para aquisição de sementes, que, às vezes, associam-se a um pacote composto por insumos (herbicidas, fungicidas e adubos).

\section{Objetivo}

O objetivo foi intensificar e dar continuidade aos trabalhos de pesquisa com foco no lançamento de cultivares, e assim, realizar a interação entre os resultados envolvendo o melhoramento do milho-pipoca da UENF e os produtores rurais das regiões Norte e Noroeste do Estado do Rio de Janeiro. Além deste objetivo, que era o principal, também existiam outros três: i) incentivar o plantio de milho-pipoca como opção rentável de diversificação de cultura; ii) despertar no produtor rural interesse pelas novas cultivares híbridas de milho-pipoca desenvolvidas pela UENF, que estavam em processo de registo pelo MAPA; iii) permitir a equipe de pós-graduandos e bolsistas de extensão, adquirir experiência com a interação da pesquisa com a extensão, reconhecendo a realidade situacional do produtor rural.

\section{Principais atividades realizadas}

No intuito de despertar o interesse dos agricultores para o cultivo de milho-pipoca, a principal estratégia adotada foi realizar um minicurso para os produtores, o qual foi oferecido durante a Semana do Produtor - realizada no Campus da UENF, por meio de minicurso. Para que fosse possível apresentar resultados e exemplares das plantas, espigas e dos grãos, foi preciso, como passo inicial, conduzir um ensaio de competição dos híbridos lançados sob as condições climáticas regionais. Após a obtenção dos resultados, o trabalho da equipe foi apresentado aos agricultores com o intuito de estimular a produção de milhopipoca.

\section{Ensaio de competição dos híbridos lançados}

Realizou-se um ensaio de competição com as cultivares citadas anteriormente na área experimental da UENF, localizada na Escola Técnica Estadual Agrícola Antônio Sarlo, Campos dos Goytacazes. A semeadura ocorreu no dia 10 de abril de 2017 (Figura 1A). O ensaio foi conduzido em blocos ao acaso, com três repetições, com oito variedades, sendo seis híbridos e duas testemunhas (VPA UENF 14 e o híbrido IAC 125) (Figura 1B). Foram utilizadas parcelas de quatro linhas com 4,0 metros de comprimento, sendo as duas linhas centrais consideradas como úteis. Utilizou-se espaçamento recomendado para a cultura, isto é, de $0,2 \mathrm{~m}$ entre plantas e $0,9 \mathrm{~m}$ entre linhas. 
Figura 1: Semeadura do ensaio de competição (A) e as plantas em estádio de florescimento masculino (B). Plantio realizado no Colégio Estadual Agrícola “Antônio Sarlo", nos meses de abril a agosto de 2017.

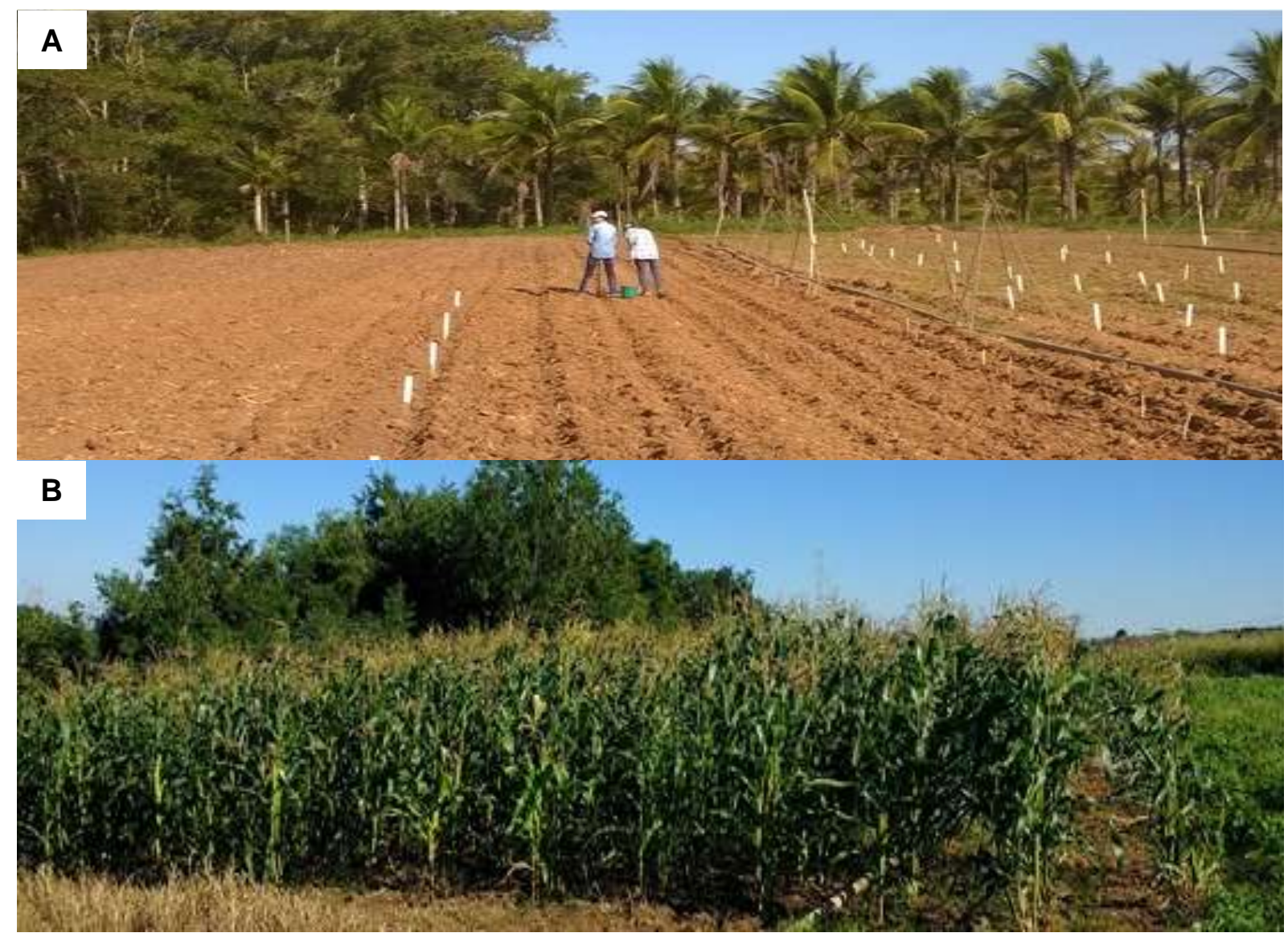

Fonte: Autores.

Durante o desenvolvimento da cultura, avaliaram-se os caracteres altura de planta, número de plantas quebradas e acamadas, número de dias para florescimento masculino (pendões liberando pólen), produtividade de grãos e capacidade de expansão. Esta última característica foi, inicialmente, aferida em balança de precisão, com a massa de $30 \mathrm{~g}$ de grãos (Figura 2A) e irradiada em microondas em saco kraft, sem óleo, por 1' 45”. O volume da pipoca foi quantificado em proveta de $2.000 \mathrm{~mL}$, sendo o quociente do volume pipocado dividido por 30 (Figura 2B). 
Figura 2: Aferição da massa de $30 \mathrm{~g}$ de grão de milho-pipoca (A) para mensurar a capacidade de expansão das cultivares avaliadas. Mensuração do volume de milho-pipoca, obtido em proveta (B).

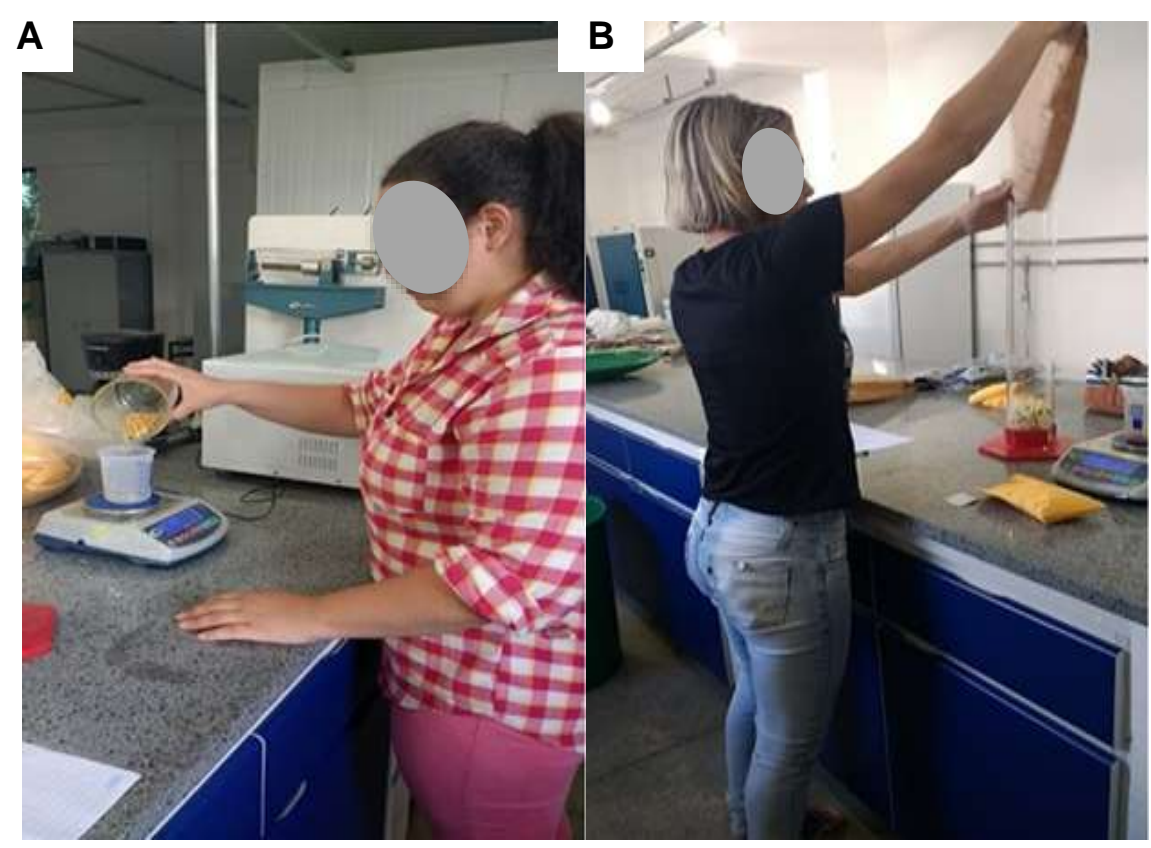

Fonte: Autores.

\section{Participação na XII Semana do Produtor Rural da UENF}

A participação no Evento foi realizada por meio dos minicursos intitulados "Adaptação do milho-pipoca à seca" e "Lançamento de cultivares de milho-pipoca para as Regiões Norte e Noroeste Fluminense". Ambos os minicursos foram organizados e dirigidos pelos estudantes bolsistas do Projeto de Extensão.

Durante o minicurso "Novas cultivares de milho-pipoca para as Regiões Norte e Noroeste Fluminense" (Figuras 3A e 3B), foram abordados temas práticos e teóricos sobre o cultivo do milho-pipoca, com enfoque para as novas cultivares desenvolvidas pelo GMMP. Além disso, explanaram-se, por meio de demonstração prática, as etapas para obtenção de uma nova cultivar de milho-pipoca, que incluíram as atividades de polinização manual (Figuras 3C e 3D). No minicurso "Adaptação do milho-pipoca à seca", foi abordada a questão das mudanças climáticas atreladas à produção de alimentos, as características relacionadas com a maior tolerância a seca e os experimentos conduzidos pela UENF para o melhoramento da cultura, no sentido de atingir-se maior tolerância à seca. A parte prática se concentrou no uso de equipamentos, como medidor portátil de clorofila, termógrafo, dentre outros, além da avaliação prática da capacidade de expansão. 
Figura 3: Apresentação dos Bolsistas no minicurso "Novas cultivares de milho-pipoca para as regiões Norte e Noroeste Fluminense" na XII Semana do Produtor Rural, da UENF (A e B). Durante a realização, demonstraram-se atividades de polinização manual (C e D).

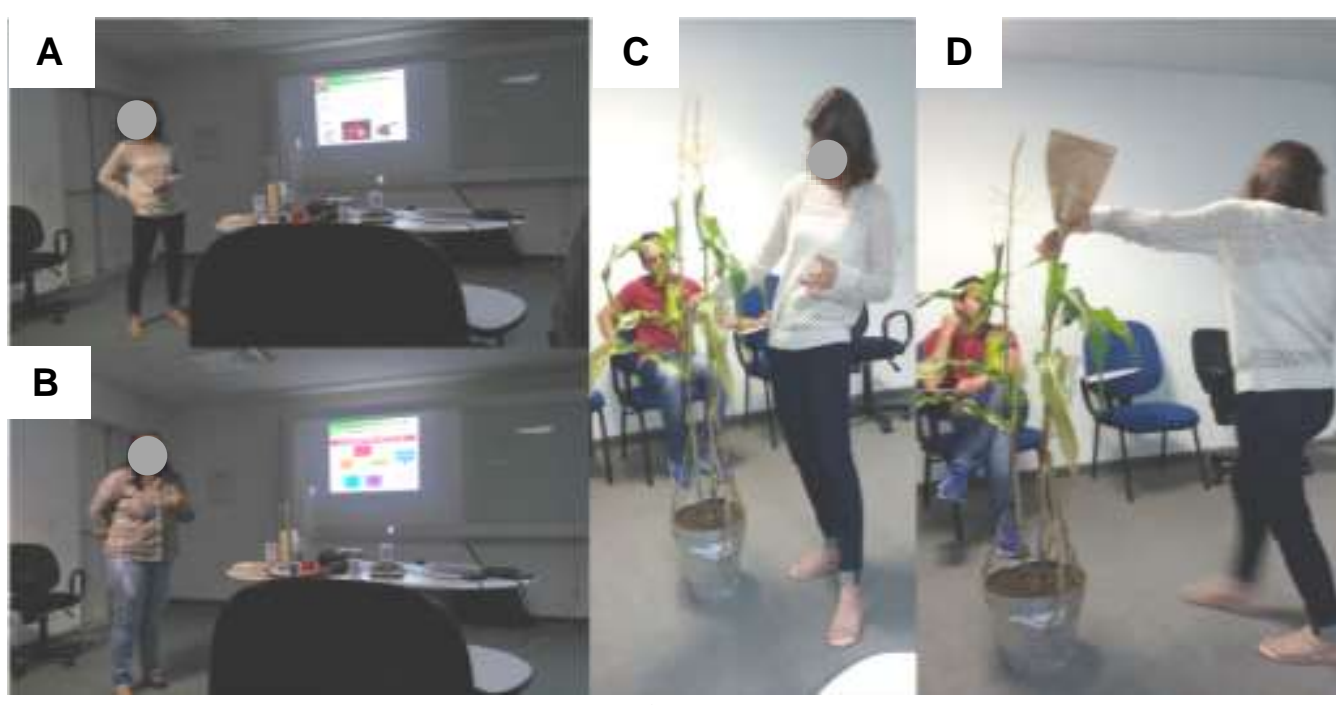

Fonte: Autores.

\begin{abstract}
Alguns resultados
A quantidade de grãos produzidos em um hectare das cultivares testadas, denominada produtividade de grãos, teve média de 4.179,51 $\mathrm{kg} \mathrm{ha}^{-1}$, semelhante à média brasileira, que é de 4.472,00 $\mathrm{kg} \mathrm{ha}^{-1}$ (Kist et al., 2019). Não houve diferença estatística no desempenho de produção dos híbridos e das testemunhas, indicando que todos possuem boa produção. Por outro lado, os híbridos lançados apresentaram média de acamamento e quebramento de plantas 1,5 vezes menor quando comparados às testemunhas.
\end{abstract}

Todas as cultivares avaliadas atingiram ou superaram o valor mínimo de $30 \mathrm{~mL} \mathrm{~g}^{-1}$ de capacidade de expansão, que é um valor considerado por Matta e Viana (2001) como recomendado. Esse bom resultado dos materiais testados mostra que são boas opções de cultivo para a agricultura local.

\title{
Principais percepções
}

O GMMP foi surpreendido no Evento, dada a baixíssima adesão dos agricultores aos cursos oferecidos. Era esperado que os agricultores buscassem mais informações sobre as novas culturas desenvolvidas para a região. No entanto, o principal público participante dos minicursos foi composto por estudantes de Agronomia da UENF. Diante disto, repensaram-se as estratégias abordadas até aquele momento. Houve o entendimento do GMMP de que seria necessário adotar estratégias mais incisivas, a fim de se obter êxito na maior proximidade com o produtor rural. A abordagem a ser realizada constitui em "Universidade para o Agricultor" e não o oposto. Necessitava-se realizar o movimento de ir até os produtores, até mesmo em suas propriedades, se necessário.

Após diversas reuniões internas realizadas, concluiu-se que seria necessária maior troca e proximidade com o públicoalvo e que as atuais ações deveriam ser reinventadas. Fazia-se necessário um movimento físico da Universidade em direção aos comerciantes e aos produtores do município de Campos dos Goytacazes com a intenção de possibilitar melhor interação com os mesmos. De fato, a estratégia de convidar os agricultores para a Universidade não se mostrou eficaz e, por esse motivo foi indispensável a mudança tática para que os objetivos fossem alcançados. A agricultura voltada para a pecuária e a cana-de-açúcar são impedimentos para o plantio do milho-pipoca, devido à cultura regional, que se encontra estabelecida até os dias atuais. O 
GMMP percebeu a necessidade de convencimento dos agricultores da importância da diversificação do cultivo para a sustentabilidade da terra.

Ainda, durante a realização do minicurso, percebeu-se que os produtores possuem grande preocupação em relação à seca, visto que a região é caracterizada por precipitações mal distribuídas ao longo do ano, o que impacta a produção agrícola. Na ocasião, os agricultores participantes se queixaram de prejuízos em suas lavouras, caso não houvesse um sistema de irrigação para garantir a máxima produtividade de suas culturas agrícolas. Todavia, isso gera maiores custos e investimentos na propriedade.

O relato dos agricultores com a seca na região, atrelado ao fato de que o GMMP possui uma linha de pesquisa com o mesmo tema, levou à percepção de que essa seria uma oportunidade de maior interação com a comunidade local, possibilitando um novo projeto com essa temática. Neste contexto, a nova estratégia adotada pelo GMMP foi ir até os comerciantes e os produtores rurais. Já o próximo passo em direção a nova abordagem foi dado com o projeto do ano seguinte.

\subsection{Perfil da cadeia produtiva do milho-pipoca e potencial de variedades para tolerância à seca: buscando estratégias em parceria com os produtores e comerciantes (ano 2018)}

A região Norte Fluminense caracteriza-se por apresentar baixa pluviosidade e distribuição irregular de chuvas, elevando o custo com irrigações para o bom êxito da produção agrícola. Não apenas em nível regional, existe uma demanda crescente por cultivares adaptadas aos períodos de seca, para, então, prover as necessidades de opções de cultivos rentáveis pelos produtores. Considerando o contexto local do Norte Fluminense, devem-se destacar alguns aspectos, quais sejam: i) a região do Norte Fluminense, em especial, o município de Campos dos Goytacazes, é uma localidade ímpar para o consumo de pipoca, dada a elevada quantidade de "carrocinhas" distribuídas pelos bairros da cidade; ii) essa região é afetada por longos períodos de escassez dos recursos hídricos, o que pode representar um entrave para o desenvolvimento pleno da cultura, bem como a aceitação de cultivo desse tipo de cultura nos estabelecimentos rurais locais e; iii) a presença da UENF, que possui um Programa de Melhoramento Genético focado no lançamento de novas cultivares de milho-pipoca, com linha de pesquisa para tolerância a seca.

Traçar um perfil socioeconômico dos comerciantes que trabalham em carrocinhas de pipoca em diversas áreas da cidade de Campos dos Goytacazes torna-se fundamental para compreender a dinâmica comercial e o quantitativo de produto que circula no município. A título de informação, Campos dos Goytacezes está localizado na região Norte Fluminense, possui uma área territorial de 4.032,48 km² sendo a cidade com maior extensão territorial do Estado do Rio de Janeiro. Sua população é de 511.168 pessoas, o que torna a cidade mais populosa do interior (IBGE, 2020). Conhecida como a capital do petróleo e do açúcar, Campos abriga a maior plataforma petrolífera do país (P-51). As características edafoclimáticas desse município tornam a região interessante para a prática da agricultura e pecuária (Campos Dos Goytacazes, 2018). Não por acaso, a economia local teve seu foco primário no gado e nas plantações e engenhos de cana-de-açúcar (Silva, 2004; Furtado, 2007).

Existe entendimento consensual dos pesquisadores do GMMP que antes de atingir os produtores e consumidores de milho-pipoca é de extrema importância compreender a dinâmica do comércio de pipoca na região (Xavier et al., 2019). Por essa razão, direcionou-se a pesquisa/extensão para conhecer os comerciantes e seu perfil. Nesse sentido, surgiram alguns questionamentos, a saber: Quais as características de uma pipoca considerada como boa? Qual a origem dos grãos comercializados no município? Qual valor monetário está atrelado a esta atividade? Qual o volume de pipoca consumida na cidade, comercializado por meio das carrocinhas? (Xavier et al., 2019). 


\section{Objetivos}

Adquirir conhecimento sobre o perfil socioeconômico do produtor rural do Norte Fluminense, com enfoque no cultivo do milho-pipoca; conhecer o perfil socioeconômico do comerciante de milho-pipoca da região Norte Fluminense; avaliar o potencial agronômico de quinze VPAs em condição de déficit hídrico, por meio da suspensão da irrigação.

\section{Metodologia aplicada e principais atividades realizadas}

Aplicaram-se questionários pré-estruturados aos comerciantes de pipoca distribuídos pelos bairros de maior fluxo popular. As entrevistas foram iniciadas em junho e finalizadas em agosto de 2018, totalizando 46 questionários aplicados (Xavier et al., 2019). Na Figura 4, observam-se dois dos estabelecimentos entrevistados.

Figura 4: Estabelecimentos comerciais de pipoca que foram alvo de entrevistas no bairro Centro, em Campos dos Goytacazes, Rio de Janeiro. A - Carrinho Água na Boca; B - Carrinho de pipoca, sem identificação.

A

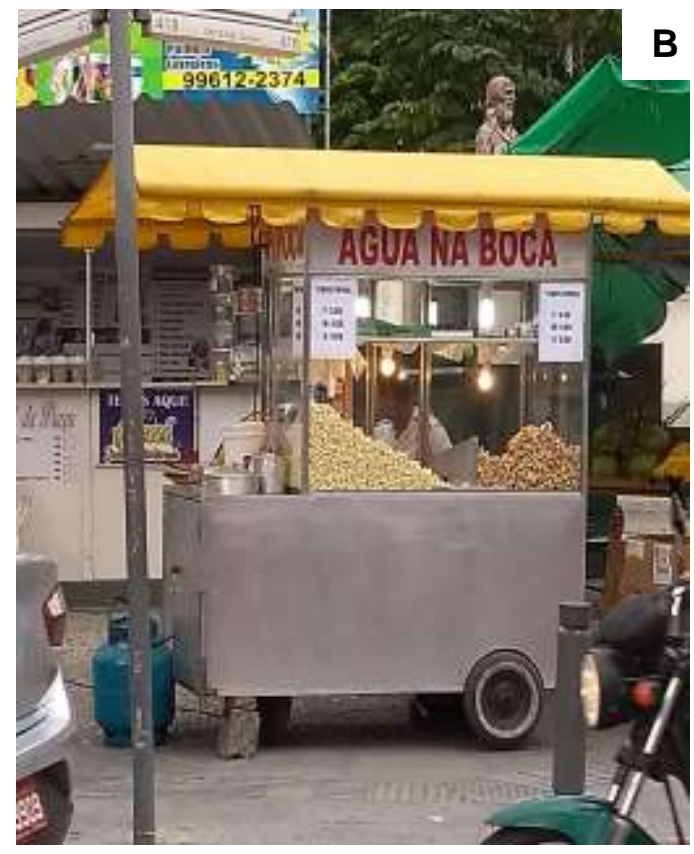

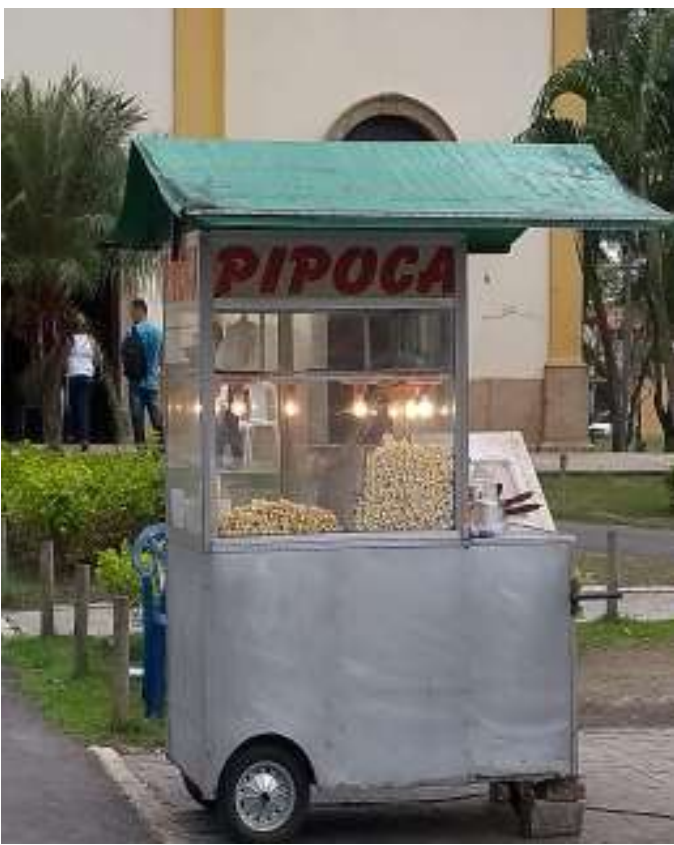

Fonte: Autores.

Os questionários encontravam-se estruturados em quatro eixos. No primeiro, denominado "perfil socioeconômico", indagou-se o comerciante quanto ao nome do carrinho, naturalidade, idade, nível de escolaridade, quanto tempo trabalha com pipoca, se possui outro trabalho e, em caso positivo, qual? Buscou-se saber se a principal fonte de renda dos comerciantes é a pipoca e quantas pessoas trabalham no estabelecimento. No segundo, intitulado "comércio de pipoca", perguntou-se qual a origem dos grãos para abastecimento do estoque; qual a marca do milho-pipoca utilizada; qual a quantidade de grãos que o comerciante estoura por dia e quantos quilogramas, em média, foram comprados por mês; quem mais consome pipoca, a saber, crianças, mulheres, homens, idosos; quais características os clientes mais gostam na pipoca, a saber, se com queijo, com bacon, ou doce, ou a pipoca pura. Ademais, questionou-se se o estabelecimento é fixo, se é próprio e se a prefeitura oferece algum apoio e, em caso positivo, qual? O terceiro eixo tratou das características do milho-pipoca utilizado, a saber: Qual a cor dos grãos utilizados; o que é uma pipoca boa, com as seguintes categorias: a) possui boa capacidade de expansão; b) não deixar piruá (grão de milho-pipoca que não estoura); c) sabor; d) cor e; e) outros, onde, os comerciantes deveriam ranquear suas características prioritárias. No quarto eixo, abordou-se sobre o conhecimento dos comerciantes em relação ao programa de melhoramento de milho-pipoca da UENF e se há interesse em adquirir o milho desenvolvido pela UENF e produzido por produtores locais, bem 
como quais as características importantes que este milho-pipoca, quais seja, preço, boa capacidade de expansão, sabor, cor, outros. Os comerciantes tiveram que ranquear suas características prioritárias.

\section{Alguns resultados}

Como principais resultados, destaca-se que cerca de 5.030,00 Kg de milho-pipoca foram adquiridos mensalmente pelos comerciantes entrevistados. Quando somados, gera um custo em torno de $\mathrm{R} \$ 15.341,50$ para a aquisição dos grãos. Estes grãos foram comprados em embalagens de 23,00 Kg, da marca "Panda Pop", majoritariamente adquiridos no Mercado Municipal. Os carrinhos de pipoca são a principal fonte de renda dos comerciantes e que existem, em média, há cerca de 10,7 anos. Na opinião dos pipoqueiros, para que o produto atenda as expectativas torna-se necessário não deixar piruá e possuir bom preço.

Existe grande interesse dos comerciantes de pipoca na utilização do milho-pipoca desenvolvido pela UENF, em parceria com produtores locais, dadas as respostas positivas a esse questionamento. Todavia, torna-se necessário que haja qualidade do grão e bom preço de venda. Sendo assim, é importante ressaltar que de posse destas informações, o cultivo de milho-pipoca pode ser concebido como uma boa opção para os agricultores locais, levando-se em consideração a possibilidade de haver um público que consumirá a produção. Como o consumo da cidade é elevado, e que apenas considerou os comerciantes entrevistados, desconhecendo o consumo populacional, esta pode ser inclusive, uma opção de melhoria de renda para os produtores.

\section{Principais percepções}

Percebendo o quantitativo de milho-pipoca que foi comercializado mensalmente no município, nota-se que esse tornase um bom incentivo aos agricultores locais para o cultivo de milho-pipoca. Este fato se deve à ampla aceitação do produto por parte da população campista, que consome grande quantidade de pipoca rotineiramente. Observa-se pelas ruas da cidade pessoas com saquinhos de pipoca e filas que se formam pelas inúmeras carrocinhas distribuídas nos bairros. Por este motivo, a produção de milho-pipoca por parte dos produtores da região é um nicho promissor de mercado. Uma boa estratégia é compartilhar esses resultados com os agricultores locais, com o intuito de comprovar a existência de um mercado potencial. Existindo possíveis compradores, a produção poderá se tornar promissora.

Além disso, como estratégias de interação para com os comerciantes locais de pipoca, pode-se considerar: oferecimento de minicursos, organização de feiras, disponibilidade de produtos para teste e distribuição de material gráfico informativo.

\subsection{O milho-pipoca como opção de cultivo rentável aos agricultores de Campos dos Goytacazes (ano 2019)}

Oitenta e nove por cento dos comerciantes de milho-pipoca possui interesse na aquisição de grãos das variedades desenvolvidas pelo GMMP, desde que possua preço atrativo e boa capacidade de expansão (Xavier, 2019). Isso gera muito otimismo, pois os comerciantes entrevistados adquirem todos os meses cerca de $5.000 \mathrm{Kg}$ de milho-pipoca na própria cidade (Xavier, 2019). Por este motivo, o GMMP acredita na boa rentabilidade do cultivo de milho-pipoca, se adotado pelos agricultores de Campos dos Goytacazes, por existir destino para o produto colhido.

Com o intuito de iniciar uma cadeia produtiva de milho-pipoca na região, o GMMP buscou realizar entrevistas com os produtores regionais, especificamente no Assentamento Zumbi dos Palmares.

\section{Objetivos}

Conhecer o perfil socioeconômico do produtor rural do Norte Fluminense, com enfoque no cultivo do milho-pipoca, e promover reunião com produtores agrícolas do município de Campos dos Goytacazes, como ferramenta incentivadora ao cultivo. 


\section{Metodologia aplicada e principais atividades realizadas}

Realizaram-se 47 entrevistas (Figura 5 - A, B, C e D) no Assentamento Zumbi dos Palmares (distribuídos pelas cinco agrovilas/núcleos/glebas denominadas Zumbi 1, Zumbi 2, Zumbi 3, Zumbi 4 e Zumbi 5), localizado nos municípios de Campos dos Goytacazes e São Francisco do Itabapoana, com os agricultores que lá residem. Aplicaram-se os questionários previamente estruturados entre os meses de setembro a outubro de 2019 (Lamêgo et al., 2019).

Figura 5: Entrevistas com agricultores no Assentamento Zumbi dos Palmares realizadas em 2019. A - Antônio das Dores Cruz, no Assentamento Zumbi IV. B - Maria da Gloria da Silva Maciel, no Assentamento Zumbi I. C - José Antônio Ferreira, no Assentamento Zumbi II. D - Luciano da Boa Morte Valentim, no Assentamento Zumbi IV.
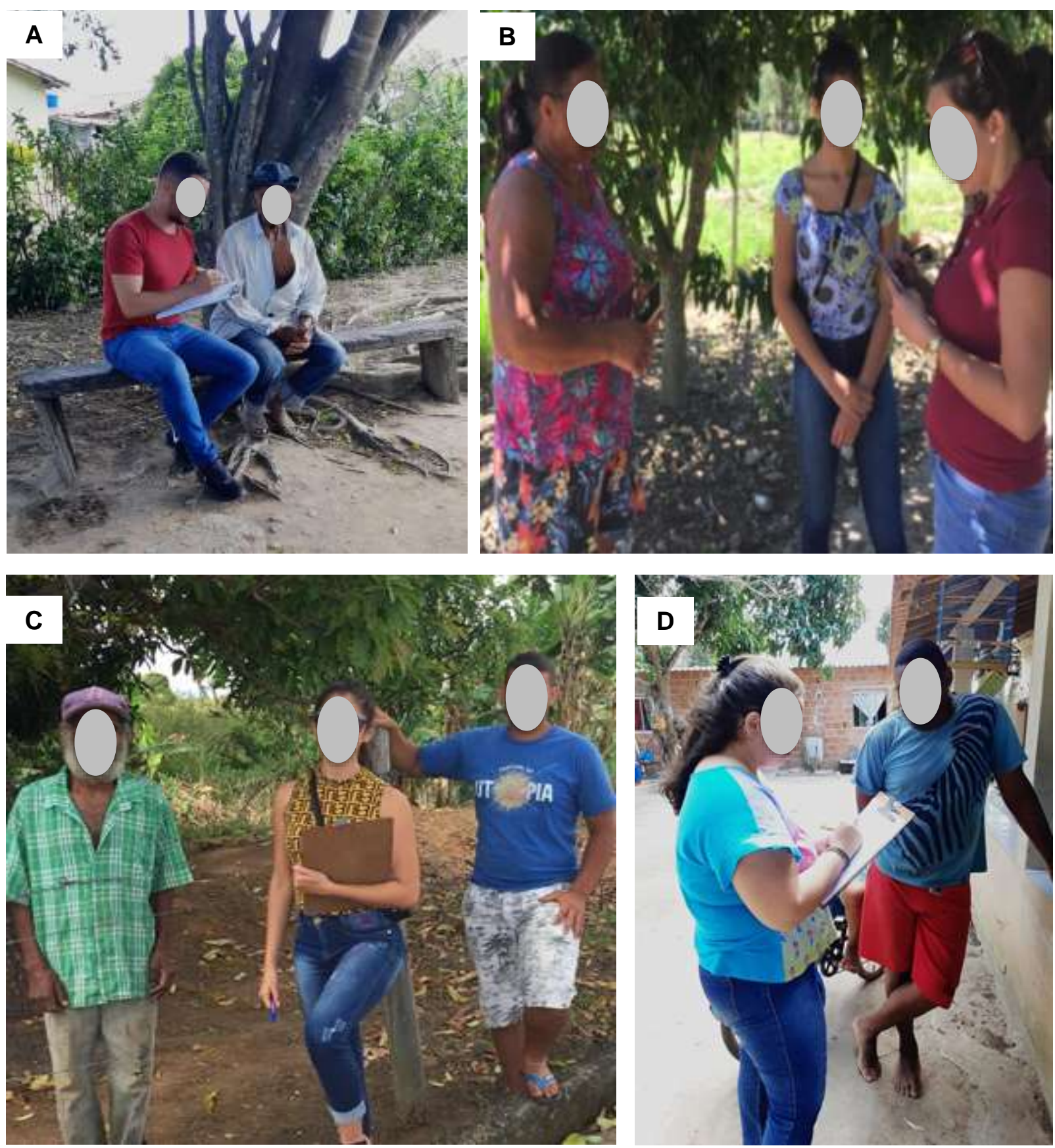

Fonte: Autores. 
Os eixos das entrevistas foram divididos de acordo com o plantio anterior de milho-pipoca, a saber: Cultiva o milhopipoca? Alguma vez o cultivou? Não cultiva? E nos últimos dois casos: possui interesse no cultivo?

Por meio dos questionários aplicados, indagou-se: nome do agricultor; naturalidade; idade; nível de escolaridade; comunidade/município de residência; tempo de residência na localidade atual; participação em cursos, se a resposta for positiva, quais; quanto tempo trabalha com pipoca; tamanho da propriedade; culturas que são produzidas; quais são comercializadas; onde são comercializadas; como são comercializadas; quem e quantas pessoas cultivam a área; tipo de mão-de-obra (familiar ou terceirizada); participação em associações ou recebimento de algum tipo de assistência, se a resposta for positiva, qual; planta milho-pipoca? E, para essa última arguição, as opções foram: sim, não ou já plantei.

Destinado a quem planta o milho-pipoca, foram feitos os questionamentos: É comercializado? Onde e como são comercializados? Qual o nome da variedade e de onde veio a semente? Qual a cor do grão e por quanto tempo planta esta pipoca? Do que mais gosta na pipoca? Qual a área/quantidade ocupada com pipoca? Quem planta, colhe e guarda as sementes? Como são plantadas e em que época? A variedade é afetada por pragas ou doenças? Aplica algum tipo de produto químico ou fertilizantes? Utiliza irrigação? Costuma armazenar as sementes para a safra seguinte? Como armazena? Tem algum problema no assentamento? Faz algum tipo de seleção para obtenção das sementes? Tem mais gente na comunidade que planta pipoca? Lembra de algum tipo de milho-pipoca que era comum no passado e agora não se encontra mais em cultivo? E se aceita disponibilizar uma amostra de semente desse tipo de pipoca para a UENF?

Reservado para quem plantou milho-pipoca alguma vez, questionou-se: Quanto tempo atrás? Por quanto tempo? Origem do material, com as seguintes opções: agropecuária, familiares, empresa, prefeitura, universidade, vizinhos, feira ou encontro e outros? Por que parou? Para essa arguição, as alternativas foram: não produzia, perdi a semente, falta de mercado, substitui por outra, falta de assistência, falta de água, não rentável e outros.

Dirigindo-se ao público que não planta milho-pipoca, abordou-se o motivo pelo qual não planta, com as seguintes alternativas: desconhece a cultura; falta chuva; dificuldade para adquirir as sementes; não possui terra; não compensa (rentabilidade); variedades pouco produtivas; falta de comércio; não tem interesse; falta de assistência técnica e outros.

Destinado a quem não planta milho-pipoca, indagou-se se havia interesse. Caso a resposta fosse positiva, questionouse: Por que haveria o interesse em cultivar? Como alternativas de resposta ao seu interesse na produção de milho-pipoca, o entrevistado teria como opção: o mercado; possibilidade de manter as sementes de um ciclo para o outro; ciclo rápido da cultura; possibilidade de autoconsumo; cultura de fácil cultivo; diversificação da lavoura; lucrativo e outros. Quando indagados sob quais condições aceitariam iniciar o cultivo do milho-pipoca em suas propriedades, as possíveis alternativas foram: receber assistência técnica; condições para implementar sistema de irrigação; disponibilidade de sementes; boa produção; capacitação; rentável; outros. Por fim, questionou-se se conhece alguém interessado. E, se sim, quem? Onde encontrá-lo? Tem interesse em desenvolver um cultivo de milho-pipoca, em parceria com a UENF, em sua propriedade?

\section{Alguns resultados}

Compreenderam-se importantes questões acerca da agricultura praticada no Assentamento Zumbi dos Palmares e a possibilidade de inserção do cultivo de milho-pipoca no local. Destaca-se que as culturas cana-de-açúcar e abacaxi são as mais cultivadas no local, sendo a comercialização da produção realizada para usinas e por meio de "atravessadores". O tamanho médio da propriedade é de 9,6 hectares, os quais, majoritariamente são cultivados pela própria família.

Quanto ao perfil socioeconômico dos agricultores, 27 entrevistados são naturais de Campos dos Goytacazes, 14 são de outros municípios e 6 nasceram em outros estados do Brasil. A faixa etária predominante foram os adultos (25-59 anos), com 25 entrevistados, seguido pelos idosos (superior a 60 anos) com 21 pessoas e por último, apenas 1 entrevistado era jovem (15-24 anos). Quando questionados quanto ao nível de escolaridade, 36 agricultores responderam que possuem apenas o nível 
fundamental, 7 possuem o ensino médio, 1 agricultor possui graduação e 3 não frequentaram a escola. Levando-se em consideração o tempo de ocupação do assentamento, que é de 22 anos, os entrevistados foram questionados em relação ao tempo que moram no mesmo. 29 agricultores são moradores antigos (16-22 anos de ocupação), 13 ocupam a classificação média (6-15 anos) e 5 agricultores moram recentemente no assentamento (0-5 anos).

A seção do questionário dedicada para as características relacionadas ao cultivo e comercialização, indagou os agricultores primeiramente quanto as atividades e culturas produzidas. 19 trabalham com grandes culturas, 16 produzem frutíferas, 5 cultivam legumes, 3 praticam pecuária, 2 trabalham com produtos de origem animal, e 2 agricultores, outros. Quanto aos locais de comercialização, 14 agricultores vendem sua produção para uma usina, 11 se utilizam de atravessadores, 6 agricultores comercializam diretamente com o consumidor final, 5 agricultores comercializam com os mercados 5 agricultores comercializam em feiras, 2 participam de cooperativas e 4 para outros locais. A força de trabalho das famílias é composta majoritariamente pela família, como citado por 39 entrevistados. 3 alunos terceirizam a mão-de-obra e 5 utilizam mão -de-obra familiar e terceirizada.

Quando questionados pelo histórico de cultivo do milho-pipoca, 40 produtores nunca cultivaram, 6 já cultivaram e 1 ainda cultiva. Fato curioso deve-se à origem da única variedade cultivada; trata-se de uma doação de semente e interação antiga da Universidade com o agricultor. Segundo as respostas obtidas, há interesse por parte dos agricultores em cultivar o milhopipoca desenvolvido pelo GMMP. 31 agricultores, ao todo. Por fim, o desconhecimento da cultura e a dificuldade para aquisição de sementes foram apontados como os principais motivos da ausência de cultivos regionais, sendo apontado por 17 agricultores (Lamêgo et al., 2019).

\section{Principais percepções}

Percebeu-se que o uso de variedades de polinização aberta (VPA) é a melhor opção para o uso pelos agricultores, decorrente da típica agricultura familiar que praticam. Além disso, cita-se a possibilidade de os produtores poderem utilizar as sementes para replantio, tornando-os independentes da aquisição de sementes de empresas. A cultivar UENF 14 se adequa às necessidades do referido público por ser uma VPA, além de ser uma variedade, com bom rendimento de grãos e boa capacidade de expansão.

Considerando que existe o interesse dos agricultores locais em cultivar milho-pipoca em seus estabelecimentos agrícolas, delinear-se-ão as seguintes estratégias: promoção de reuniões, palestras e minicursos, distribuição de Cartilha "O cultivo do milho-pipoca na região Norte-fluminense", a ser desenvolvida pelo GMMP, bem como, a distribuição de sementes.

\subsection{Popularizando o cultivo de milho-pipoca no Assentamento Zumbi dos Palmares, Campos dos Goytacazes: a} Universidade promovendo ações incentivadoras e transferindo tecnologia por meio da distribuição de sementes (ano 2020)

Os dois últimos Projetos de Extensão (2018 e 2019) do GMMP se dedicaram a compreender a dinâmica do consumo, comercialização e produção de milho-pipoca no município de Campos dos Goytacazes. Como o desconhecimento da cultura e a dificuldade para aquisição de sementes foram apontados como os maiores entraves para o cultivo, o GMMP pretendeu eliminar estas lacunas e encorajar a produção. No intuito de satisfazer as necessidades dos entrevistados, o GMMP entende que é necessário encurtar a distância que existe entre a Universidade e a comunidade. E foi nesse sentido que o projeto do ano de 2020 foi concebido. Chega-se o momento em que o GMMP considera mais importante na tentativa de iniciar uma cadeia produtiva de milho-pipoca na região, a distribuição de sementes aos agricultores. 


\section{Objetivos}

Promover palestras, minicursos e a distribuição de cartilhas e de sementes, no sentido de popularizar e incentivar o cultivo de milho-pipoca na região, elevando a possibilidade de aceitação da cultura; e conhecer as principais dificuldades para o cultivo, os tratos culturais e as práticas de seleção aplicadas e, principalmente, o destino dos grãos produzidos.

\section{Resumo da metodologia aplicada até o momento}

Devido às medidas de distanciamento social necessárias e seguidas no momento, em decorrência da pandemia por Covid19, tanto interação internas, quanto aquelas externas, foram realizadas, majoritariamente, em formato on line. Coletivamente, a confecção da cartilha "Milho-pipoca na região Norte Fluminense", bem como de mídias incentivadores vêm sendo realizadas virtualmente. Contatou-se via telefone os agricultores interessados no cultivo, aqueles antes diagnosticado, para combinar a entrega das sementes e da cartilha, bem como solicitou-se a autorização para inclusão em grupo no WhatsApp para contato posterior. A distribuição ocorreu por meio de um assentado, vinculado voluntariamente ao Projeto, visto ser considerada a forma mais segura. As sementes doadas advêm da variedade UENF14, que possibilita replantio e possui recomendação regional. O Grupo possui 32 agricultores, os quais são motivados, quinzenalmente, por meio de mídia. Relata-se engajamento dos agricultores, visto depoimento de informações sobre área a ser plantada, preparo de solo praticado, dentre outros. Como perspectivas cita-se a continuidade de publicação de arte, bem como a aplicação de questionário para investigar o destino das sementes, além de conhecer o manejo cultural e o destino da produção, além de outras informações.

\section{Resultados esperados}

Espera-se estimular o cultivo de milho-pipoca por parte dos agricultores, a princípio, os moradores do assentamento Zumbi dos Palmares, localizado no município de Campos dos Goytacazes. Acredita-se que ambientalmente também haverá benefícios ao se aplicar novas práticas sustentáveis de manejo da terra, como a diversificação de culturas. Ademais, no âmbito social, o projeto visa que a nova cultura inserida no assentamento represente uma fonte de renda alternativa. Uma nova renda permite a movimentação da economia local, além de representar acesso a novas formas de consumo para os agricultores. O programa possui o interesse em manter proximidade com a população ao promover reuniões, cursos e assistências, a fim de auxiliar os produtores a cultivar as variedades de milho. Como consequência, a interação com os assentados agregará novos conhecimentos ao Programa de Melhoramento de Milho-pipoca da Universidade Estadual Norte Fluminense Darcy Ribeiro, haja vista o compilado de novas informações obtidas sobre as características, peculiaridades, entraves e aptidões particulares à agricultura das regiões Norte e Noroeste Fluminense, antes desconhecidas.

\section{Conclusões}

Até o momento, as valiosas informações obtidas por meio dos Projetos de Extensão demonstram a viabilidade do cultivo do milho-pipoca por parte dos moradores do Assentamento Zumbi dos Palmares, uma vez que haja capacitação, assistência técnica e disponibilização de sementes. Caso os agricultores consigam comercializar o produto com preço competitivo, os comerciantes de pipoca da cidade também poderão se beneficiar ao adquirir um produto de qualidade com menor ou igual preço do atual produto comercializado, que vem a ser importado.

\section{Referências}

Alexander, D. E., \& Creech, R. G. (1977). Breeding special industrial and nutritional types. In: Sprague, g. F.; fuccillo, d. A. (Ed.). Corn and corn improvement. Madison: American Society of Agronomy, p. 363- 386. (Agronomy, 18). 
Azevedo, J. H. Uma análise da cadeia produtiva de cana-de-açúcar na Região Norte Fluminense. In: PESSANHA, R. M.; SILVA NETO, R. (orgs.) (2004). Economia e Desenvolvimento no Norte Fluminense. Da cana-de-açúcar aos royalties do petróleo. Campos dos Goytacazes, RJ: WTC Editora.

BBM (2020), Bolsa Brasileira de Mercadorias. Cotações agrícolas. https://www.bbmnet.com.br/cotacoes-agricolas.

Brugnera, A., Pinho, R. G., Pacheco, C. A. P., \& Alvarez, C. G. D. (2003). Resposta de cultivares de milho pipoca a doses de adubação de semeadura. Revista Ceres, 50 (290), 417-429.

Brunson, A. M. (1937). Popcorn breeding: Yearbook Agricultural, 1: 395-404.

Cabral, P. D. S., Amaral Júnior, A. T. D., Freitas, I. L. D. J., Ribeiro, R. M., \& Silva, T. R. D. C. (2016). Relação causa e efeito de caracteres quantitativos sobre a capacidade de expansão do grão em milho-pipoca. Revista Ciência Agronômica, 47(1), 108-117.

Campos Dos Goytacazes, P. M. (2018). Perfil Campos dos Goytacazes 2018. Campos dos Goytacazes - RJ: [s.n.].

Carpentieri-Pípolo, V., Takahashi, H. W., Endo, R. M., Petek, M. R., \& Seifert, A. L. (2002). Correlações entre caracteres quantitativos em milho pipoca. Horticultura Brasileira, 20(4), 551-554.

Daros, M., Amaral Júnior, A. T. D., Pereira, M. G., Santos, F. S., Scapim, C. A., Júnior, F., \& Ávila, M. R. (2004). Correlações entre caracteres agronômicos em dois ciclos de seleção recorrente em milho-pipoca. Ciência Rural, 34(5), 1389-1394.

De Lima, V. J., Do Amaral Junior, A. T., Kamphorst, S. H., Pena, G. F., Leite, J. T., Schmitt, K. F., Vittorazzi, C., De Almeida Filho, J. E., \& Mora, F. (2016). Combining ability of S3 progenies for key agronomic traits in popcorn: comparison of testers in top-crosses. Genetics and Molecular Research. 15(1), 1-16.

Faria, V. R., Viana, J. M. S., Sobreira, F. M. \& Silva, A. C. (2008). Seleção recorrente recíproca na obtenção de híbridos interpopulacionais de milhopipoca. Pesquisa Agropecuária Brasileira, 43(12), 1749-1755.

Freitas Júnior, S. P., Amaral Júnior, A. T., Rangel, R. M., \& Viana, A. P. (2009). Genetic gains in popcorn by full-sib recurrent selection. Crop Breeding and Applied Biotechnology, 9,1-7.

Furtado, C. (2007). Formação econômica do brasil. 34a .ed. São Paulo: Companhia das letras, caps. 1 a 29, p. $25-248$.

Galerani, P. (2005). Perdas repetidas. Cultivar, 7(76), 42-45.

Hallauer, A., \& Carena, M. J. (2009). Maize Breeding. In: Cereals. ed.: Carena, M.J. Springer. 425p.

IBGE (2020). Instituto Brasileiro de Geografia e Estatística. Cidades e Estados. Rio de Janeiro, RJ: https://www.ibge.gov.br/cidades-e-estados/rj/campos-dosgoytacazes.html.

INCRA, Superintendente do Incra RJ promove reunião com núcleos do assentamento Zumbi dos Palmares. 2011. http://www.incra.gov.br/pt/superintendentedo-incra-no-rj-promove-reuniao-com-nucleos-do-assentamento-zumbi-dos-palmares.

Kist, B. B., Carvalho, C., \& Beling, R. R. (2019). Anuário brasileiro do milho 2019; Beling, R. R., Ed.; Editora Gazeta: Santa Cruz do Sul; ISBN $1808-3439$.

Lamêgo, D. L., Kamphorst, S. H., Carvalho, C. M., Silva, R. M. R., Silva Júnior, S. B., Figueiredo, J. S. M., Lima, V. J., \& Amaral Júnior, A. T. (2019). O milho-pipoca como opção de cultivo para os agricultores de Campos dos Goytacazes. Revista de Extensão da UENF, 4(3), 36-55.

Lewin, H. (2005). Uma nova abordagem da questão de terra no Brasil: o caso do MST em Campos dos Goytacazes. Rio de Janeiro. 7 LETRAS.

Matta, F. P., \& Viana, J. M. S. Testes de capacidade de expansão em programas de melhoramento de milho pipoca. (2001). Scientia Agricola, Piracicaba, 58 (4), 845-851.

Ministério da Agricultura, Pecuária e Abastecimento. (2020). Registro nacional de cultivares.

Silva, O. P. 500 anos dos Campos dos Goytacazes. Campos dos Goytacazes, RJ. (2004). Fundação Cultural Jornalista Oswaldo Lima.

Pedlowski, M. A., Aquino, S. L., Canela, M. C., \& Silva, I. L. A. (2006). Um estudo sobre a utilização de agrotóxicos e os riscos de contaminação num assentamento de reforma agrária no Norte Fluminense. Journal of the Brazilian Society of Ecotoxicology, 1(2), 185-190.

Xavier, K. B., Kamphorst, S. H., Carvalho, C. M., Silva, R. M. R., Silva Júnior, S. B., Lima, V. J., \& Amaral Júnior, A. T. (2019). Comércio de Milho-Pipoca na Região Norte Fluminense e Características Apreciadas no Produto. Revista de Extensão UENF, 4(2), 22-35. 